Conclusion Quality and quantity of sleep was affected in children aged 3-15 years. Low birth weight children are at a greater risk of suffering from poor sleep quality. However, this finding is to be confirmed in larger study.

\section{G397(P) A RARE CASE OF UVULITIS}

${ }^{1}$ E Yousif, ${ }^{2}$ AP Petkar. ${ }^{1}$ Paediatric, UHNM, Stoke on Trent, UK; ${ }^{2}$ Paediatric, Russells Hall Hospital, Dudley, UK

\subsection{6/archdischild-2020-rcpch.341}

An isolated Uvulitis, or edema of the uvula is infrequently reported. ${ }^{1}$ This condition sometimes develops as a consequence of anaphylaxis and angioedema. In nearly half of cases, no etiology is apparent.

The present study examines the case of a 12-year-old girl, admitted with an inability to speak or swallow saliva. The symptoms developed over several hours prior to her admission. In the evening, she experienced gagging and vomiting. The patient provided a history of unable to swallow saliva and drooling large amounts, no pain in the throat or difficulty breathing. The examination revealed a swelling in the back of her throat. The findings are consistent with the diagnosis of uvulitis. Interestingly, the patient had dyed her hair prior to developing her symptoms. She was initially treated with IV dexamethasone in the emergency department and two additional doses were provided in the ward. The patient was also started on intravenous co-amoxiclav and intravenous fluid because of the difficulty swallowing and was subsequently seen by the ENT team. Her symptoms improve overnight and eventually, she was discharged home on oral Phenoxymethylpenicillin with a follow-up.

Overall, the case is interesting on two levels- it highlights this uncommonly reported disorder with the potential for significant morbidity. Additionally, the physician should be cautious in attributing dysphagia or respiratory distress to uvulitis alone, because of the recognized association with epiglottitis ${ }^{2} 3$ or allergy. 4

Future research should focus on assessing the causes of uvulitis as well as the diverse symptoms that may be experienced by patients in response to this infection.

\section{REFERENCES}

1. Uvilitis in three children: Etiology and respiratory distress, Victor Aquino, MD, Thomas E. Paediatric emergency care, August 1992.

2. Jerrard D.A., and Olshaker J.: Simultaneous uvulitis and epiglottitis without fever or leukocytosis. Am J Emerg Med 1996;14:551-552.

3. Lathadevi H.T., Karadi R.N., Thobbi R.V., et al: Isolated uvulitis: an uncommon but not a rare clinical entity. Indian J Otolaryngol Head Neck Surg 2005;57: 139-140.

4. Strome M (Editor): differential diagnosis in Paediatric otolaryngology. Boston, Little Brown\&Co, 1975, P 110.

\section{G398(P) STRENGTHENING OF JUNIOR DOCTORS THROUGH SHARED LEARNING OF EVIDENCE BASED PAEDIATRICS}

MBKC Dayasiri, S Rao. Department of Paediatrics, Oxford University Hospital, Oxford, UK

10.1136/archdischild-2020-rcpch.342

Background Journal Club is an education platform for junior doctors and it is highly useful for sharing knowledge and practice which in turn leads to improved care. However, this forum was infrequently held, poorly attended and given less priority and trainees had less interest according to 2018 online survey at department of paediatrics, John Radcliffe hospital, Oxford.

Methods Journal Club was conducted over one year with incorporation of new organisational measures. Trainees invited to present in Journal Club and trainee had the ownership of the choice of article. Presenters encouraged with formal written feedbacks for their e-portfolio. Junior doctors were guided but had their own choice for selecting themes. Each session was advertised by regular weekly emails to improve attendance. Resource articles were distributed in advance to promote discussion and peer learning. Online survey was conducted to assess the impact of the changes after thirteen months following these interventions.

Results Fifty weekly Journal Clubs were held over 13 months. 55 junior and senior trainees presented with presentation rate being 93\%. Thirty trainees and consultants responded to online survey. $87 \%$ were satisfied about session length. 100\% believed topics were relevant. $96 \%$ believed the journal club was at least somewhat relevant to their clinical practice. $100 \%$ believed the alert emails were useful. 100\% believed resource articles were at least somewhat helpful.

Conclusion Provision of written feed backs, regular and friendly reminders for participation, and distribution of resources articles prior to Journal Club meeting were associated with improved participation and overall satisfaction among both presenters and attenders.

\section{G399(P) ABSTRACT WITHDRAWN}

\section{G400(P) NURTURING YOUR INNER CHILD: PAEDIATRIC STAFF WELL-BEING PROGRAMME}

${ }^{1} \mathrm{~T}$ Benzaken, ${ }^{2} \mathrm{~L}$ Roe, ${ }^{2} \mathrm{R}$ Talker, ${ }^{3} \mathrm{E}$ Fukari-Invine, ${ }^{2} \mathrm{~B}$ Williams. ${ }^{1}$ General Paediatrics and Neonatology, Northwick Park Hospital, London, UK; ${ }^{2}$ General Paediatrics, Northwick Park Hospital, London, UK; ${ }^{3}$ Neonatology, Northwick Park Hospital, London, UK

\subsection{6/archdischild-2020-rcpch.343}

Aims Evidence has shown that doctors' well-being and mental health is increasingly affected by rising demands on their workloads. ${ }^{1}$ Low morale and high stress levels are increasingly leading to trainee burnout. ${ }^{2}$ Paediatrics has seen a yearly decline in the workforce since $2015 .^{3}$ Applicants for paediatric training fell from 800 in 2015 to 580 in $2017,,^{3}$ contributing to an average rota vacancy rate of $14 \%{ }^{3}$ We aimed to set up a paediatric staff activity programme, in a busy district general hospital, to increase staff well-being and improve morale in the work-place.

Methods Between September 2018 and August 2019 we implemented an activity programme to all staff members across the paediatric department, introducing a variety of activities including yoga, hip-hop and running club. All sessions were run by trainees and were catered to suit all abilities. Sessions took place in hospital grounds and were free of charge. The sessions initially ran on a monthly basis, but the frequency was later increased. 
Results 40 paediatric staff members across all training grades participated in the well-being programme. Staff members provided feedback on the classes via an anonymised questionnaire. $100 \%$ of respondents 'strongly agreed' that the sessions improved team morale and bonding. All respondents either 'agreed' or 'strongly agreed' that they found the sessions beneficial. However, half of respondents either 'neither agreed or disagreed' or 'disagreed' that sessions helped reduce burnout. Key limitations of the project included, reduced attendance rate when classes occurred outside of normal working hours and difficulty ensuring consistency of classes (classes were run by trainees and so were dependent on their workload).

Conclusions Exercise has a proven benefit in improving wellbeing and work related mental health problems. ${ }^{4}$ This quality improvement project has shown a demand for introducing work-based activities and that it is beneficial and well regarded by paediatric staff. However, limitations regarding sustainability of such a programme need to be addressed in order to ensure longevity of the project and further work is needed to address whether this tackles the root cause of burnout.

\section{REFERENCES}

1. NHS Survey Coordination Centre 2018, Health \& Wellbeing CQUIN, viewed 1 September 2019, <www.nhsstaffsurveys.com/page/1064/latest-results/2018-results>

2. Carolyn Wickware 2018, GMC expresses concerns over trainee doctor burnout, Pulse, viewed 26 August 2019, <www.pulsetoday.co.uk/news/gp-topics/education/gmc-expresses-concerns-over-trainee-doctor-burnout/20037055.article>

3. RCPCH 2017, Short report series: The Paediatric Workforce, State of Child Health, viewed 2 August 2019, <www.rcpch.ac.uk/sites/default/files/2018-03/ 2015 rcpch state of child health the paediatric workforce v1.1.pdf $>$

4. Mind 2014, How to promote wellbeing and tackle the causes of work-related mental health problems, viewed 1 October 2019, <www.mind.org.uk/media/ 428496/Resource3_HowToPromoteWellBeingFINAL.pdf\&gt;

\section{G401(P) ROYAL COLLEGE CONFERENCE PANELS OVER THE LAST FIVE YEARS: HOW INCLUSIVE HAVE THEY BEEN?}

${ }^{1} \mathrm{~K}$ Prathivadi Bhayankaram, ${ }^{2} \mathrm{~N}$ Prathivadi Bhayankaram. ${ }^{1}$ Clinical School, University of Cambridge, Cambridge, UK; ${ }^{2}$ Department of Paediatrics, Royal Manchester Children's Hospital, Manchester, UK

\subsection{6/archdischild-2020-rcpch.344}

Background In early 2019, the issue with 'manels' was highlighted. This prompted us to look into how widespread the problem is. We wanted to examine the conferences of the UK medical Royal Colleges over the past five years to assess the diversity of the keynote speakers.

Methods We identified the fourteen main UK Royal Colleges and looked up their conference programmes from 2015 to 2019. We examined the proportion of keynote/plenary session speakers who were male and female and who were Caucasian or from Black and ethnic minority (BME) backgrounds.

Results Out of 70 conferences, we were able to access programmes from publicly available data for 20 (29\%) conferences for eight Royal Colleges. The RCPCH conference programmes are only available for the previous year, making trends for our College difficult to examine.

In $60 \%$ of conferences there was a predominance of male speakers and in $15 \%$ there were an equal number of female and male speakers. The overall trend was of an increasing equality in the number of male and female speakers from 2015 to 2019 . In terms of ethnicity, only $10 \%$ of conferences had an equal number of BME and Caucasian speakers. There was a mean of $2 \mathrm{BME}$ speakers and 8 Caucasian speakers per conference. The trend from 2015 to 2019 did not show any improvement in BME participation.

Discussion Our findings show that there has been an increase in the number of female speakers at Royal College annual conferences over the last five years however there is still some way to go. We also need to improve the proportion of BME speakers. We need to encourage conference organisers to think about equality and diversity when they plan for meetings. We also need to explore possible barriers for women and BME speakers; is it that they are not given the opportunity or are there reasons for which they are unable to take up these opportunities? We also need to encourage more Royal Colleges, like the RCPCH, to publish data on conference panels and to allow conference programmes to be publicly available.

\section{G402(P) A REVIEW OF OUR LOCAL EXPERIENCES WITH THE SUPPORTT RETURN TO TRAINING POLICY: IS IT WORKING IN PRACTICE?}

${ }^{1} \mathrm{M}$ Keane, ${ }^{2} \mathrm{~S}$ Ogden, ${ }^{3} \mathrm{~L}$ Wade, ${ }^{4} \mathrm{~A}$ Jobling, ${ }^{5} \mathrm{~F}$ Mehta. ${ }^{1}$ Community Paediatrics, Mid Cheshire Hospitals NHS FT, Crewe, UK; ${ }^{2}$ Community Paediatrics, Warrington and Halton Hospitals NHS FT, Warrington, UK; ${ }^{3}$ Neonatal Unit, Liverpool Women's NHS FT, Liverpool, UK; ${ }^{4}$ General Paediatrics, Stockport NHS FT, Stockport, UK; ${ }^{5}$ Diabetes Service, Alder Hey Children's NHS FT, Liverpool, UK

\subsection{6/archdischild-2020-rcpch.345}

Background Health Education England has introduced a Supported Return to Training (SuppoRRT) policy advocating additional provision for returning trainees. This echoes feedback previously presented from local trainees demonstrating need for increased training resources. Following the introduction of a local RTT policy in 2018 we aimed to evaluate uptake to inform further resource provision.

Methods Online questionnaire to all educational supervisors and all trainees taking time-out-of-training across deanery.

Results Currently, we have responses from 15 educationalsupervisors and 11 trainees.

$82 \%$ trainees and $87 \%$ educational-supervisors were aware of the policy; most trainees learnt about it during time-out. This was reflected by the $64 \%$ of trainees who did not arrange a pre-absence meeting or make any advance plans for anticipated needs on returning. Many limitations were discussed regarding keeping-in-touch (KIT) days. Post-absencereview meetings were reported by $44 \%$ of trainees and $86 \%$ of educational supervisors. Supportive measures were arranged by $66 \%$ of trainees to aid return. A period of supervised-oncalls on return was reported by $86 \%$ of supervisors but no trainees, with $75 \%$ deeming it unnecessary. $78 \%$ of trainees and $43 \%$ of supervisors did not report confirming-readinessto-practice meetings before usual on-calls resumed. $57 \%$ of supervisors were unaware of SuppoRRT-funding available to meet specific training needs.

Overall $91 \%$ trainees and $87 \%$ of educational-supervisors found that the RTT policy was working well, either partly (64\% and 47\%) or mostly (27\% and $40 \%)$. Both trainees and supervisors felt that the policy improved trainee wellbeing $(57 \%$ and 57\%), trainee development (42\% and 21\%) and patient safety (71\% and 64\%). Comparing responses from our previous survey, following implementation of the policy there was a reduction in trainees feeling 'unnecessarily exposed' from $76 \%$ to $27 \%$.

Conclusion Overall there are positive responses on the new RTT policy, although the method introduces inherent bias. 